\title{
HIGH-TEMPERATURE DEFORMATION BEHAVIOR OF HIGH-NB MICROALLOYED STEEL DURING PLATE ROLLING SIMULATION
}

\author{
Samuel Filgueiras Rodrigues ' \\ Fulvio Siciliano ${ }^{2}$ \\ Clodualdo Aranas Júnior ${ }^{3}$ \\ Eden Santos Silva ${ }^{\prime}$ \\ Gedeon Silva Reis ' \\ John Joseph Jonas ${ }^{4}$
}

\begin{abstract}
When austenite is deformed above the $\mathrm{Ae}_{3}$ temperature, partial amount of it transforms dynamically into ferrite by a displacive mechanism. After unloading, it retransforms back into the stable austenite by a diffusional process. This phenomenon influences the rolling load, which either decreases under isothermal rolling condition or does not progressively increase with decreasing temperature during cooling. In this work, plate rolling simulations employing isothermal and continuous cooling conditions were carried out on a $0.09 \mathrm{wt} . \% \mathrm{Nb}$ X-70 steel. Pass strains in the range of 0.2-04, interpass times between $10-30 \mathrm{~s}$ and strain rate of $\mathrm{Is}^{-1}$ were employed. The results showed that the critical strains for the initiation of dynamic transformation fell around 0.06 while the critical strain for dynamic recrystallization was 0.12 . Under cooling conditions, the ferrite formation is favored as the temperature approaches the $\mathrm{Ae}_{3}$ line. Such ferrite forms when the driving force for dynamic transformation is higher than the total free energy barrier. Increasing the holding time after rolling increases the amount of austenite available for microstructure control on subsequent stages. The dynamic transformation (DT) mechanism can be used to design improved rolling schedules.
\end{abstract}

Keywords: Dynamic transformation; High Nb steel; Plate rolling simulation.

\section{INTRODUCTION}

When austenite is deformed during strip and plate rolling processes, part of its volume fraction transforms dynamically into ferrite $[1,2]$. This has been referred to as dynamic transformation (DT) and was first studied by Yada and co-workers in the 1980's in which, fine grains of ferrite were produced above the $\mathrm{Ae}_{3}$ temperature in plain carbon steels $[3,4]$. Later, these authors used in-situ X-ray diffraction coupled to a torsion machine with the aim to provide real-time evidence for the occurrence of DT above the $\mathrm{Ae}_{3}$. Diffraction patterns associated with $\alpha$-ferrite during deformation were captured [5].

Laser dilatometry tests were performed by Chen and Chen [6] where the reverse transformation of ferrite into austenite was observed above the $\mathrm{Ae}_{3}$. In 2007, Liu et al. [7] performed tests in a Gleeble thermomechanical simulator on a low-carbon steel and obtained metallographic results proving the existence of DT. Laser dilatometer was also performed by Sun et al. in 2008 in order to follow the reverse DT [8]. It was confirmed the existence of forward and reverse transformation at temperatures up to $115^{\circ} \mathrm{C}$ above the $\mathrm{Ae}_{3}$.

The effects of strain, strain rate and temperature on DT were investigated by Basabe and Jonas [9]. They conducted torsion tests on a $0.036 \% \mathrm{Nb}$ microalloyed steel and concluded that the reverse transformation was retarded by the addition of niobium in comparison with a plain $C$ steel. It was proposed that this phenomenon was a result from dislocation pinning and solute drag of the niobium carbonitride precipitates and $\mathrm{Nb}$ in solution, respectively.

Ghosh et al. [10], demonstrated that DT ferrite could be formed as high as $130^{\circ} \mathrm{C}$ above the $\mathrm{Ae}_{3}$ by considering that the dislocations are distributed inhomogeneous which could lead to driving forces for ferrite formation as high as $197 \mathrm{~J} / \mathrm{mol}$ when their materials were submitted to large strains. This approach had been improved by Grewal et al. [1], Aranas and Jonas [I I] and Aranas et al. [12] which explained the possible occurrence of DT as much as $500^{\circ} \mathrm{C}$ above the $\mathrm{Ae}_{3}$. Here they redefined the driving force for DT that

'Programa de Pós-Graduação em Engenharia de Materiais, Instituto Federal de Educação, Ciência e Tecnologia do Maranhão, São Luis, MA, Brasil.

E-mail: samuel.filgueiras@ifma.edu.br

${ }^{2}$ Gleeble Simulation Testing Solutions, Dynamic Systems Inc., Poestenkill, NY, United States of America.

${ }^{3}$ Department of Mechanical Engineering, University of New Brunswick, Fredericton, NB, Canada.

${ }^{4}$ Materials Engineering, McGill University, Montreal, QC, Canada.

2176-1523 (C) 2020. Rodrigues et al. Published by ABM. This is an Open Access article distributed under the terms of the Creative Commons Attribution License, which permits unrestricted use, distribution, and reproduction in any medium, provided the original work is properly cited. 
consisted only of the softening during transformation due to the applied stress. All the obstacles against the driving force for DT consisted of the Gibbs free energy difference between austenite and ferrite plus the lattice dilatation and shear accommodation works. According to this model, DT ferrite is only possible when the driving force overcomes the total barrier preventing its formation.

More recently, DT has been investigated under strip rolling process by Aranas et al. and under plate rolling conditions by Rodrigues et al. [ I - - 14]. Volume fraction of ferrite around $40 \%$ above the $\mathrm{Ae}_{3}$ and after the last passes has been found in their research. Here, the phenomenon of DT is studied under isothermal and continuous cooling conditions with interpass time of 10 and 30 s, respectively. The results obtained are described and discussed in following sections.

\section{METHODOLOGY}

An X70 steel was investigated in the present work. This material was provided in the form of hot-rolled plates. The chemical composition of the material (in wt\%) is displayed in Table I. The orthoequilibrium and paraequilibrium $\mathrm{Ae}_{3}$ temperatures were identified by employing the FSstel database of the FactSage thermodynamic software [15]. For the present analysis, the orthoequilibrium $\mathrm{Ae}_{3}$ temperature has been considered, where both the substitutional and interstitial atoms are assumed to participate during phase transformation. The plates were machined into torsion specimens with diameters of $6.35 \mathrm{~mm}$ and gauge lengths of $22.2 \mathrm{~mm}$ with their cylinder axes parallel to the rolling direction.

The experiments were conducted on a computer-controlled MTS torsion machine equipped with a radiation furnace and temperature controller. A K type thermocouple was welded to the torsion specimens for temperature measurement and control. A quartz tube enclosing the samples was employed together with a protective argon gas atmosphere to minimize oxidation and decarburization during testing.

The thermomechanical schedules for the tests under continuous cooling and isothermal conditions are illustrated in Figure I and 2, respectively.

The deformed and quenched torsion samples were sectioned perpendicular to the longitudinal axis for microscopy analysis. A conductive hot phenolic resin was used to mount the samples. These were polished using $\mathrm{SiC}$ grits 400,600 , 800 and 1200 lubricated with water. The final polishing was carried out using 3 and $\mathrm{I} \mu \mathrm{m}$ diamond suspensions. The polished surfaces were etched with $2 \%$ nital (to reveal the microstructure) followed by $10 \%$ aqueous metabisulfite ( $\mathrm{Na} 2 \mathrm{~S} 2 \mathrm{O} 5)$ solution (to provide contrast between ferrite and martensite).

\section{RESULTS}

\section{I Flow Curves}

Continuous cooling flow curves determined during the simulations are illustrated in Figure $3 \mathrm{a}$ and $3 \mathrm{~b}$ for the $10 \mathrm{~s}$ and $30 \mathrm{~s}$ interpass time results, respectively. The temperatures at which each pass was applied are also shown. All the tests were conducted above the orthoequilibrium $\mathrm{Ae}_{3}$ temperature $\left(845^{\circ} \mathrm{C}\right)$ for this steel, see Table I. The initial and final temperatures for all tests were 950 and $860^{\circ} \mathrm{C}$ respectively.

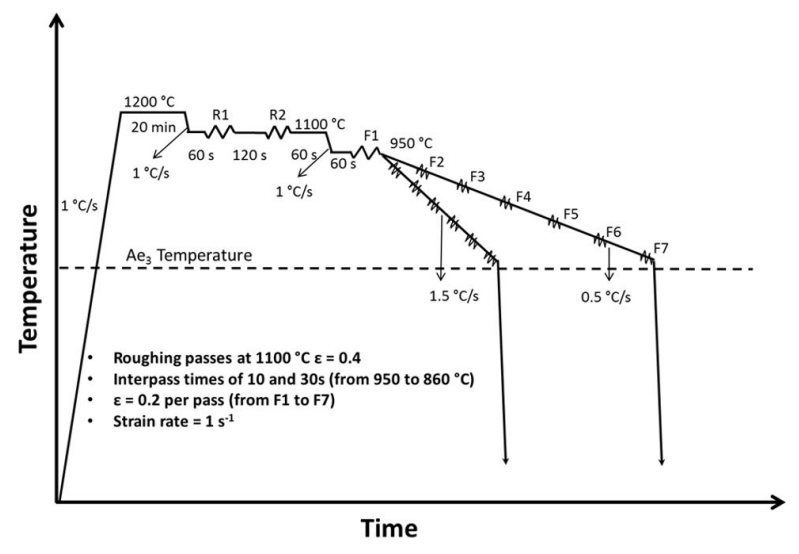

Figure I. Thermomechanical schedule employed for the continuous cooling simulations. The deformation temperatures were 950, 935, $920,905,890,875$ and $860^{\circ} \mathrm{C}$ and interpass times of 10 and 30 s were employed.

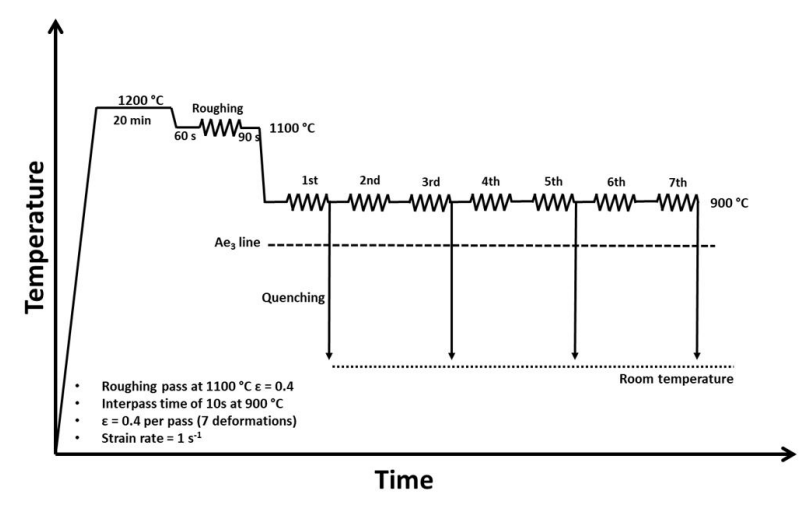

Figure 2. Thermomechanical schedule employed for the isothermal simulation. The deformation temperature was $900^{\circ} \mathrm{C}$ and interpass time of 10 s was employed.

Table I. Chemical composition (mass\%) and equilibrium transformation temperatures $\left({ }^{\circ} \mathrm{C}\right.$ )

\begin{tabular}{cccccccc}
\hline $\mathbf{C}$ & $\mathbf{M n}$ & $\mathbf{S i}$ & $\mathbf{C r}$ & $\mathbf{N b}$ & $\mathbf{N}$ & $\mathbf{O r t h o ~}^{-\mathbf{A e}_{3}}$ & $\mathbf{P a r a ~ A e}_{3}$ \\
\hline 0.047 & 1.56 & 0.25 & 0.21 & 0.092 & 0.008 & $845^{\circ} \mathrm{C}$ & $810^{\circ} \mathrm{C}$ \\
\hline
\end{tabular}



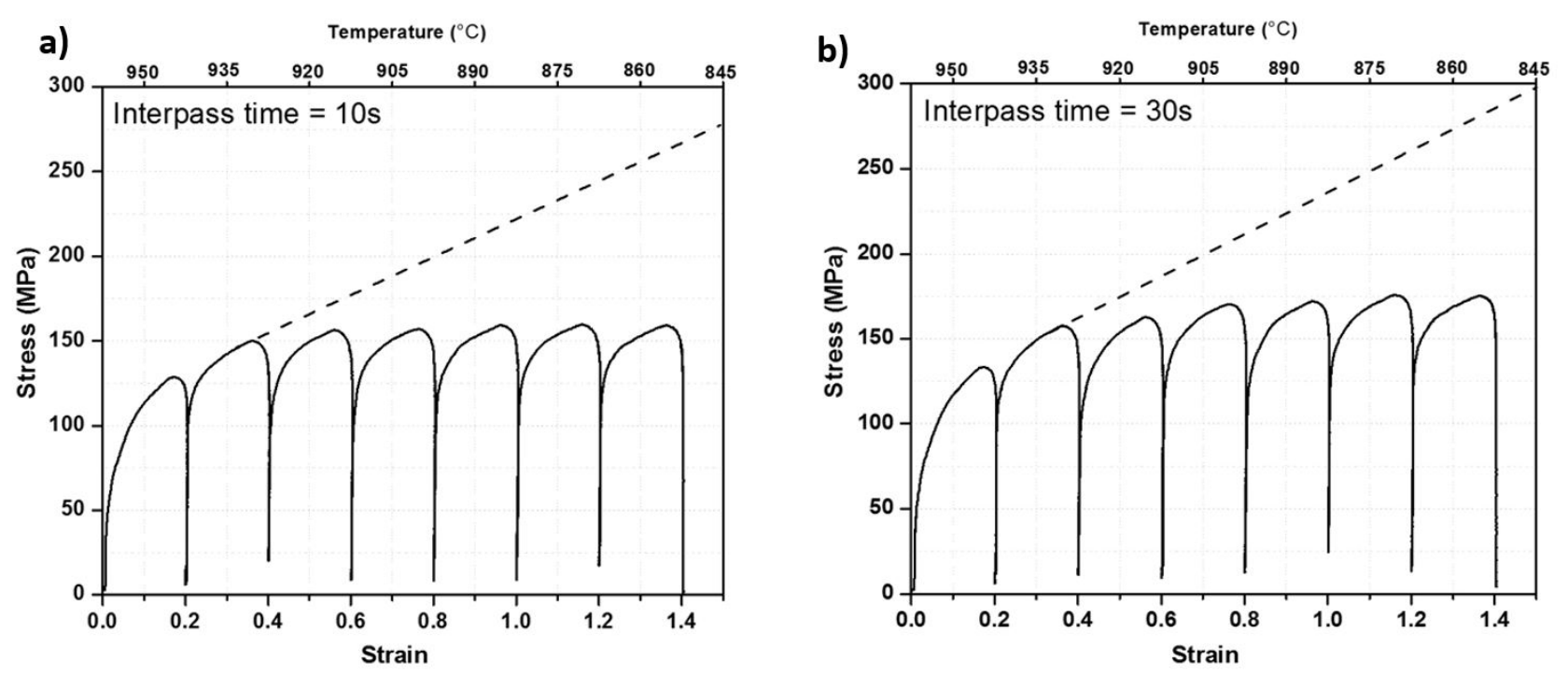

Figure 3. Stress-strain curves determined according to the schedule in Figure I using pass strains of 0.4 applied at I s $\mathrm{s}^{-1}$. Interpass times of (a) $10 \mathrm{~s}$ and (b) $30 \mathrm{~s}$.

For the 10s interval, Figure 3a, the stress levels increase slightly from the first to the fourth pass but then remain approximately constant until the seventh pass. For the 30s interpass times, Figure $3 \mathrm{~b}$, the stress levels are higher when compared to the IOs intervals and increase progressively until the last pass. The broken line represents the expected stress levels from the third to the last pass based on the second pass peak and the temperature dependence expressed.

The stress-strain curves obtained from the 7-pass simulations under isothermal condition and interpass time of 10 s are illustrated in Figure 4. No cooling was applied between passes so that no flow stress corrections were required to offset the effect of decreasing temperature. In the absence of phase transformation and of dynamic recrystallization, the flow stress levels should not change significantly from pass to pass during constant temperature deformation. However, the peak stresses decreased perceptibly from the second pass to the final pass in all the tests.

The increase in stress level for the second pass is associated with strain accumulation and the gradual decrease after this pass can be attributed primarily to the progressive formation of ferrite.

\subsection{Microstructural Results}

In the present investigation, all the ferrite volume fraction measurements were carried out on longitudinal samples taken from about $250 \mu \mathrm{m}$ below the surface of the sample. This was done so as to avoid the oxidized outer layer. The results that correspond to the $10 \mathrm{~s}$ interpass times under continuous cooling are presented in Figure 5. The ferrite is light while the martensite (prior austenite) appears dark.

It can be seen that small amounts of ferrite are already present before the first pass (Figure $5 \mathrm{a}$ ), which

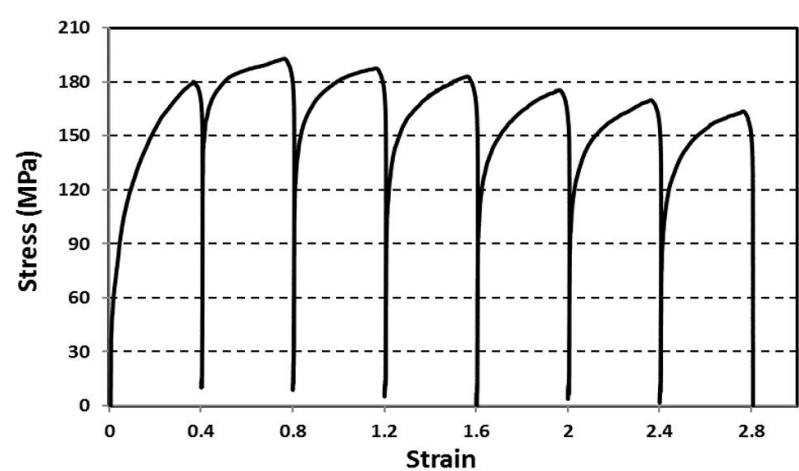

Figure 4. Stress-strain curves determined on the $X 70$ steel according under isothermal condition using pass strains of 0.4 applied at $\mathrm{I} \mathrm{s}^{-1}$ and interpass time of 10 s.

were produced during the roughing passes. The volume fraction of ferrite can be seen to increase progressively during finishing, see Figure $5 \mathrm{~b}-\mathrm{h}$, a topic that is examined in more detail below. Grain elongation is readily visible in the longitudinal micrographs, where the major axis of the grains gradually approaches the horizontal axis. This is particularly visible after the 3 th and 5 th passes.

\subsection{Mean Flow Stresses}

The role of dynamic transformation during the present simulation can be further assessed in terms of the mean flow stresses (MFS's) developed. Equation I was employed for this purpose and applied to all the flow curves in Figures 3 and 4.

$$
M F S=\frac{1}{\varepsilon_{b}-\varepsilon_{a}} \int_{\varepsilon_{a}}^{\varepsilon_{b}}\left(\sigma_{e q} d \varepsilon\right)
$$


Before
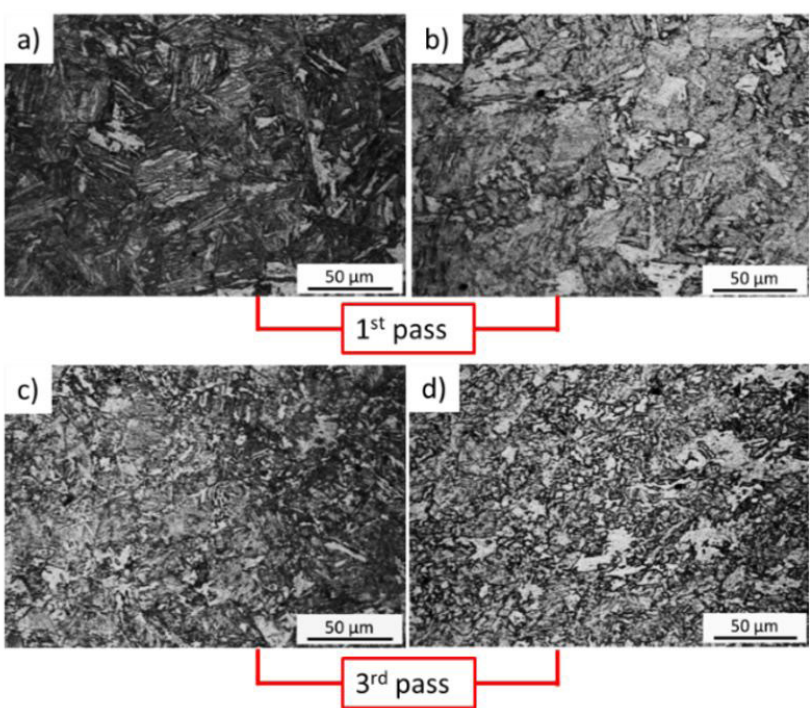
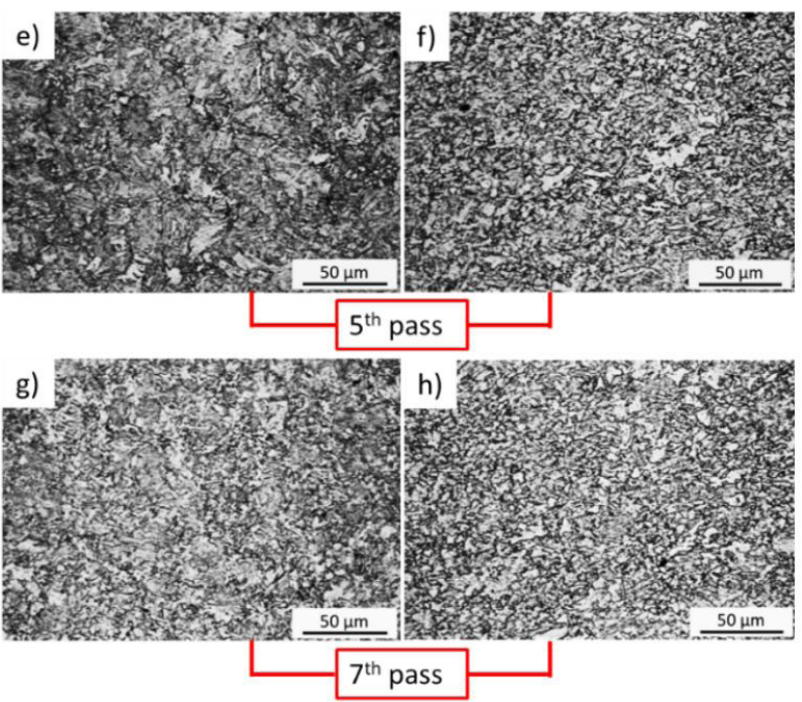

Figure 5. Optical microstructures of the steel subjected to interpass times of $10 \mathrm{~s}$ under continuous cooling condition. The samples were quenched immediately before the: (a) Ist; (c) 3rd; (e) 5th; and (g) 7th pass; and immediately after the: (b) Ist; (d) 3rd; (f) 5th; and (h) 7th pass. Light regions are ferrite while the dark regions are martensite (prior austenite).

Here, $\sigma_{\text {eq }}$ is the equivalent stress and $\left(\varepsilon_{\mathrm{b}}-\varepsilon_{\mathrm{a}}\right)$ is the equivalent strain applied in a particular pass. The results obtained in this way are presented in Figure 6 for interpass times of 10 s and 30 s under cooling and Figure 7 for isothermal conditions.

For continuous cooling conditions, see Figure 6, a sharp increase in MFS from the first to the second pass at both interpass times is presented. This is a consequence of strain accumulation and amounts to an average of about $30 \%$ in the present tests. In the later passes, involving the IOs intervals, the MFS's continue to increase but only by about $1.2 \%$ for the final passes. When the interpass time was increased to 30 s, the increases amounted to about $4 \%$ on average. The modest MFS increases from the second to the final pass for both intervals indicate that ferrite (which is softer than austenite) is being formed in each pass. It is important to note that the MFS values increase the least with falling temperature at the shorter interpass time. This is because the time available for the diffusional static retransformation of ferrite into austenite is the least under these conditions.

For the isothermal results, the MFS's drop continuously from the second or third through to the last pass, indicating that ferrite (which is softer than austenite) is being formed in each pass, see Figure 7.

\section{DISCUSSION}

\section{I Critical Strains for the Onset of DT and DRX}

To investigate the characteristics of dynamic transformation under rolling conditions, the critical strains associated with the onset of DT and DRX were determined

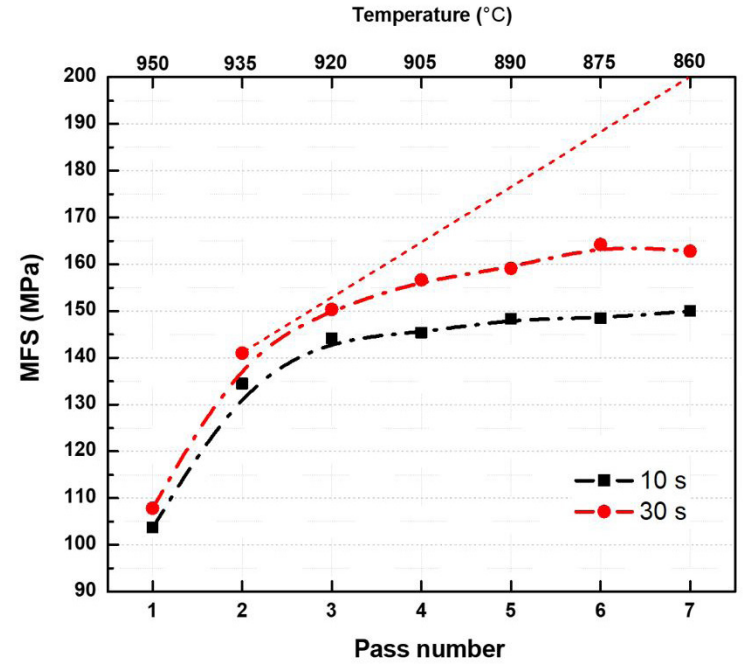

Figure 6. MFS's curves calculated from the flow curves of Figure 3 and 4. The relatively low rate of increase with decreasing temperature is a result of the formation of DT ferrite during each pass. There is strain accumulation from the Ist to the 2nd pass and less ferrite reverts to austenite when the interpass time is decreased, leading to lower MFS values.

by the double differentiation method. This was applied to the stress-strain curves of Figure 4 using the MatLab software and was done by fitting the curves from the $0.2 \%$ offset yield stress to the peak stress using a 9th order (or higher in some cases) polynomial [16]. Previous researchers have shown (by means of microstructural analyses) that the first critical point identifies the start of dynamic transformation (DT), while the second specifies that of dynamic recrystallization (DRX) $[9, \mathrm{I} I]$. These analyses have indicated that the critical strain for DT is always lower than that for DRX. 


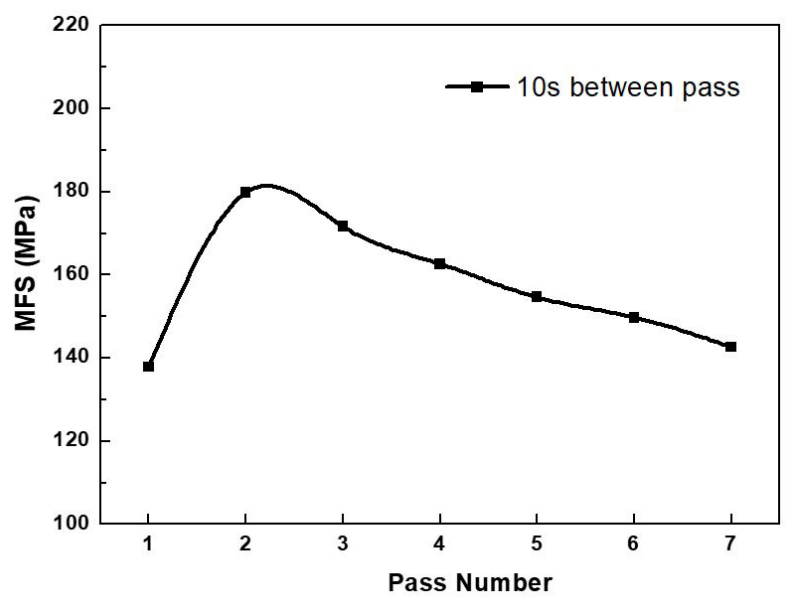

Figure 7. MFS curve derived from the stress-strain curves of Figure 4. The MFS's increase from the Ist to the 2 nd pass and then decrease in the succeeding passes. This decrease results from the formation of DT ferrite during each pass.

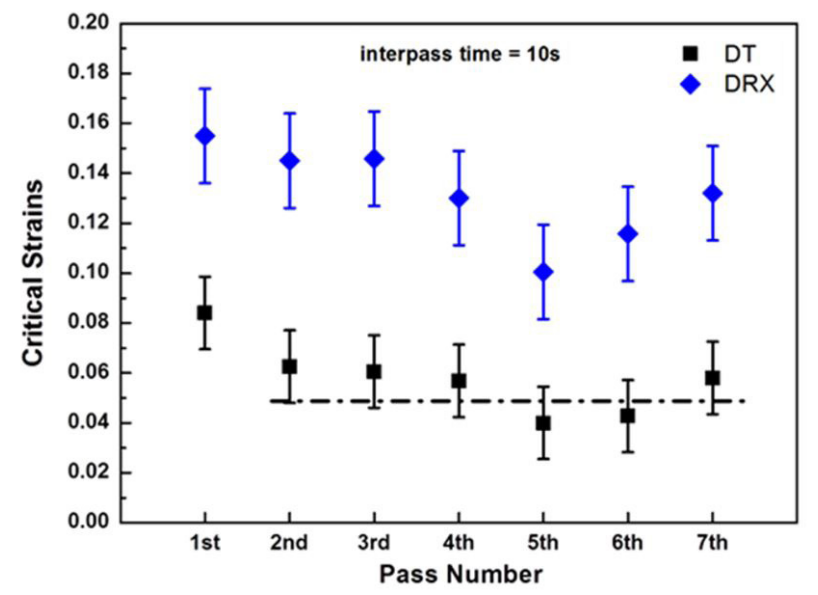

Figure 8. Critical strains for dynamic transformation (DT) and dynamic recrystallization $(D R X)$ as a function of pass number. Interpass time of $10 \mathrm{~s}$. Here the first pass always displays the highest critical strain.
The critical strains required to initiate DT and $D R X$ determined in this way are illustrated in Figure 8 for interpass time of 10 s under isothermal condition. The first pass DT critical strain (average value 0.082 ) is higher than in the succeeding passes, (average 0.045). Similar remarks apply to the DRX critical strains, as the average values were 0.15 for the first pass and 0.11 for the succeeding second to the seventh passes.

\subsection{Volume Fraction of Transformed Ferrite per Pass}

The cumulative volume fractions of ferrite present after each pass from the continuous cooling simulations are displayed in Figure $9 a$ and $9 b$ for interpass times of 10 and 30s, respectively. The quantities of ferrite before each pass are also shown here, from which the amounts that were statically retransformed can be determined. Each figure also shows the deformation temperature and cumulative strain. It should be noted that the amount of ferrite produced and retained increases with pass number and with decreasing temperature. The volume fraction of transformed ferrite increases more rapidly for the 10 s interpass times compared with the results of the $30 \mathrm{~s}$ intervals. It is evident that the roughing passes introduced some ferrite because DT ferrite volume fraction of approximately $7.5 \%$ was present before the first finishing pass.

\subsection{SEM and EBSD Analysis}

The microstructure of a torsion sample sectioned transversely after the first pass is presented in Figure 10. In torsion tests, the strain increases from zero at the center to a maximum at the surface. In Figure IOa, where the local strain is 0.08 , some plate-like ferrite can be seen coalescing into a polygonal grain. These very thin plates were formed displacively on the initiation of straining and began to coalesce into polygonal ferrite grains upon further straining.

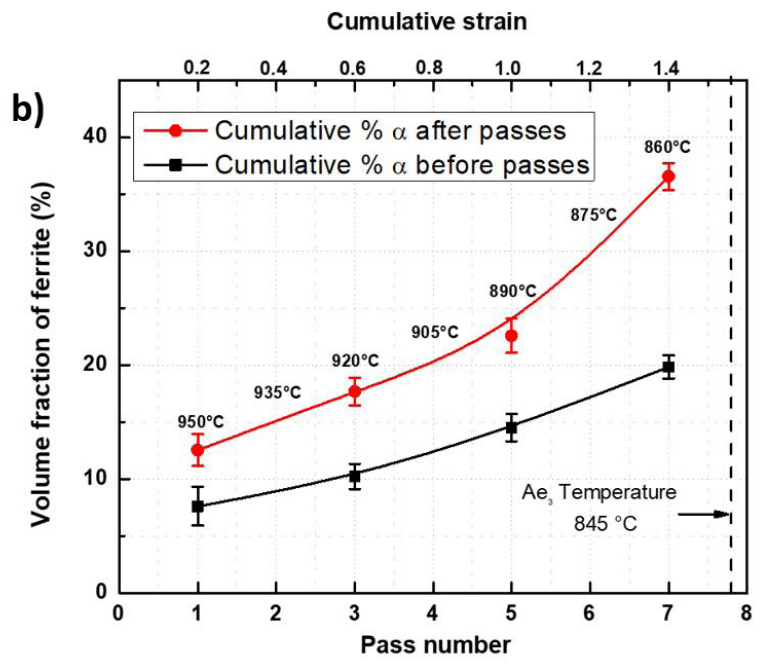

Figure 9. Dependence of the cumulative volume fraction of ferrite formed and retained on pass number and interpass time: (a) I0s and (b) 30 s. As the pass number is increased, the amounts of ferrite formed and retained increase. 

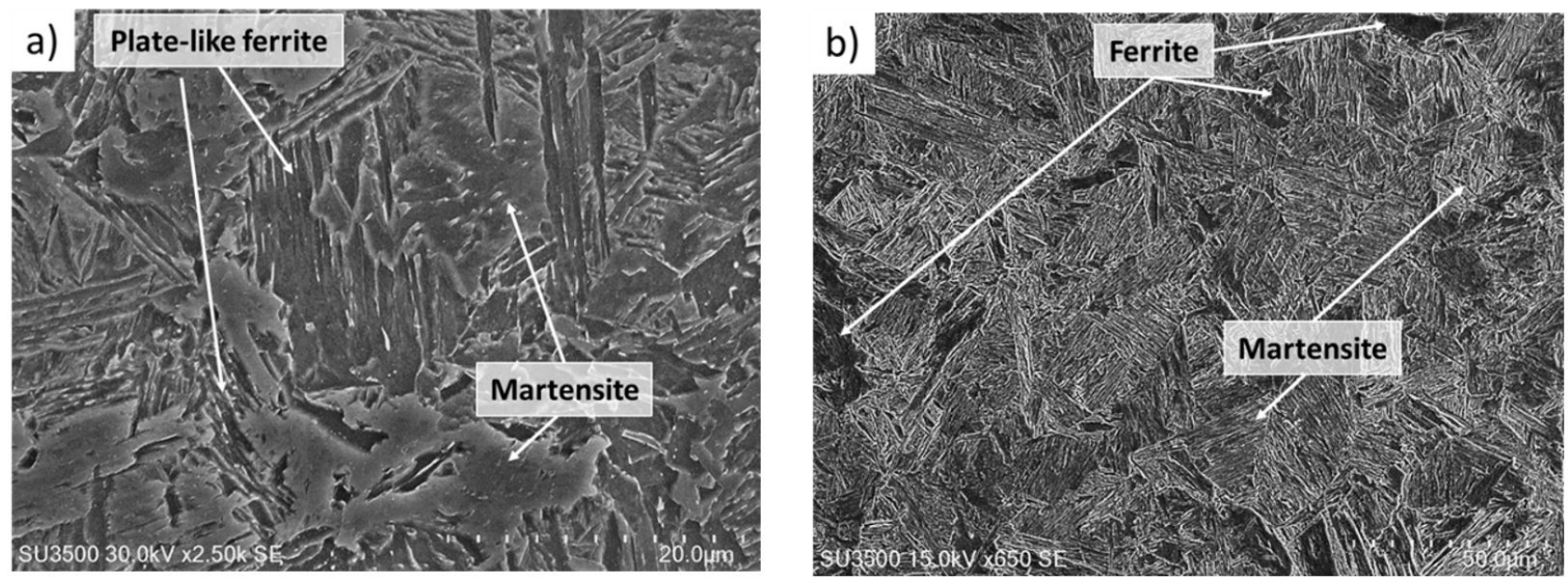

Figure 10. Microstructure of sample subjected to the first finishing pass and quenched: (a) local strain of approximately 0.08 showing plate-like ferrite coalescing into polygonal grains; (b) local strain of approximately 0.2 showing the presence of ferrite (mostly of polygonal form) and martensite (prior austenite).
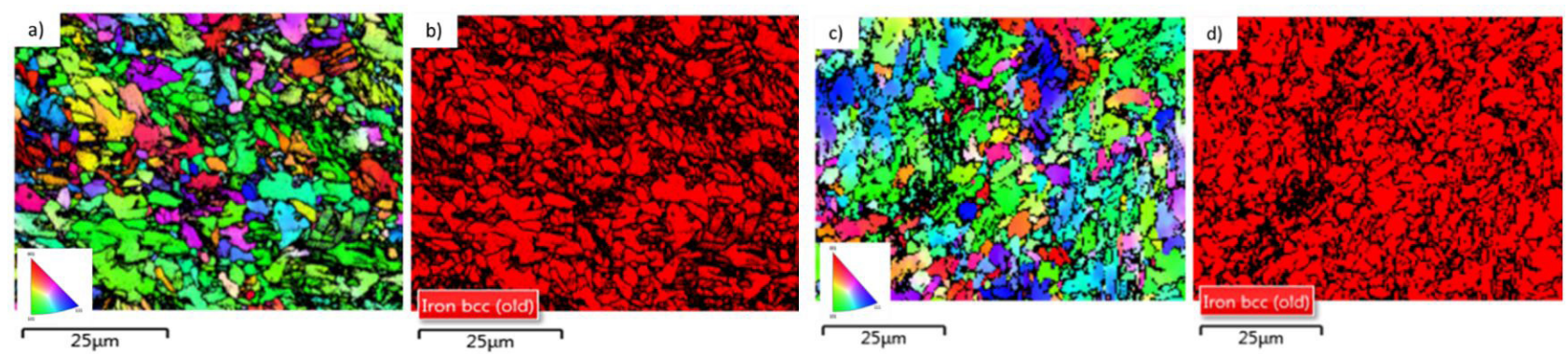

Figure I I. EBSD micrographs of transverse cross-sections of samples subjected to $10 \mathrm{~s}$ interpass times. These were quenched immediately after straining: (a) inverse pole figure colors and (b) phase identification after the 5th pass; (c) inverse pole figure colors and (d) phase identification after the 7 th pass. In (b) and (d), the ferrite phase is red while the prior austenite is black.

In Figure 10b, where the local strain is approximately 0.2, the ferrite is mostly present in polygonal form.

The large volume fractions of ferrite that form under the present conditions were confirmed using the EBSD technique of phase identification, as illustrated in Figure I I. Here, the effect of applying five passes is shown in Figure I la and I l b. The microstructure present after seven passes is shown in Figure IIc and IId. The red regions represent ferrite while martensite (prior austenite) is unindexed and appears black. Note that there is less ferrite after the fifth pass, Figure I I b, than after the seventh pass, Figure IId. This is consistent with the volume fraction measurements presented in section 3.5.

\section{CONCLUSIONS}

The occurrence of dynamic transformation during simulated 7-pass rolling has been examined and has led to the following conclusions.

I The occurrence of dynamic transformation during straining is responsible for the lack of increase in rolling load under both interpass time conditions. The large MFS increase from the first to the second pass is attributable to strain accumulation;
2. More ferrite is produced and retained when 10 s interpass times are employed than when this is increased to 30s. This is because there is less retransformation of the metastable DT ferrite into the more stable austenite during the shorter interpass times;

3. A small amount of DT ferrite is produced during roughing. The volume fraction of ferrite formed during a particular finishing pass then increases with pass number (i.e. with the retained strain and with proximity to the Ae3). It decreases with the length of the subsequent interpass interval due to retransformation;

4. The DT ferrite initially forms displacively as Widmanstätten plates. On continued straining, these plates coalesce diffusionally into polygonal grains.

\section{Acknowledgements}

The authors acknowledge with gratitude the Fundação de Amparo à Pesquisa e ao Desenvolvimento Científico e Tecnológico do Maranhão - FAPEMA, Brazilian National Council for Scientific and Technological Development (CNPq) and the PRPGI IFMA. 


\section{REFERENCES}

I Grewal R, Aranas C, Chadha K, Shahriari D, Jahazi M, Jonas JJ. Formation of Widmastatten ferrite at very high temperatures in the austenite phase field. Acta Materialia. 2016;109:23-31.

2 Aranas $\mathrm{C}$, Jung $\mathrm{IH}$, Yue S, Rodrigues SF, Jonas JJ. A metastable phase diagram for the dynamic transformation of austenite at temperatures above the Ae3. International Journal of Materials Research. 2016;107:88I-886.

3 Yada H, Matsumura Y, Senuma T. Proceedings of the International Conference on Martensitic Transformations. Sendai, Japan: Japan Institute of Metals; 1986. p. 515.

4 Yada H, Matsumura Y, Senuma T. A new thermomechanical heat treatment for grain refining in low carbon steels. In: Proceedings of the Ist International Conference on Physical Metallurgy of Thermomechanical Processing of Steels and Other Metals (THERMEC'88); 1988; Keidanren Kaikan, Tokyo, Japan. Tokyo: ISIJ; I988. p. 200.

5 Yada H, Li CM, Yamagata H. Dynamic $\gamma-\alpha$ transformation during hot deformation in Iron-Nickel-Carbon alloys. ISIJ International. 2000;40:200-206.

6 Chen Y, Chen Q. Dilatometric investigation on isothermal transformation after hot deformation. Journal of Iron and Steel Research International. 2003;10:46-48.

7 Liu Z, Li D, Lu S, Qiao G. Thermal stability of high temperature deformation induced ferrite in a low carbon steel. ISIJ International. 2007;47:289-293.

8 Sun X, Luo H, Dong H, Liu Q, Weng Y. Microstructural evolution and kinetics for post-dynamic transformation in a plain low carbon steel. ISIJ International. 2008;48:994-1000.

9 Basabe $\mathrm{V}$, Jonas JJ. The ferrite transformation in hot deformed $0.036 \% \mathrm{Nb}$ austenite at temperature above the Ae3. ISIJ International. 2010;50:I I85-II 92.

10 Ghosh C, Basabe VV, Jonas JJ, Kim Y, Jung I, Yue S. The dynamic transformation of deformed austenite at temperatures above the $\mathrm{Ae}_{3}$. Acta Materialia. 2013;61:2348-2362.

II Aranas C, Jonas JJ. Effect of $\mathrm{Mn}$ and $\mathrm{Si}$ on dynamic transformation of austenite above the $\mathrm{Ae}_{3}$ temperature. Acta Materialia. 2015;82:I-I0.

12 Aranas C, Nguyen-Minh T, Grewal R, Jonas JJ. Flow softening-based formation of Widmanstatten ferrite in a $0.06 \% \mathrm{C}$ steel deformed above the $\mathrm{Ae}_{3}$. ISIJ International. 20I5;55:300-307.

13 Rodrigues SF, Aranas C, Sun B, Siciliano F, Yue S, Jonas JJ. Effect of grain size and residual strain on the dynamic transformation of austenite under plate rolling conditions. Steel Research International. 2018;89: I-7.

14 Rodrigues SF, Aranas C, Wang T, Jonas JJ. Dynamic transformation of an X70 steel under plate rolling conditions. ISIJ International. 2017;57:162-169.

I5 Bale CW, Belisle E, Chartrand P, Decterov SA, Eriksson G, Hack K, Jung IH, Kang YY, Melancon J, Pelton AD, et al. FactSage thermomechanical software and database-recent developments. Calphad. 2009; 33: 295-3II.

16 Ghosh C, Aranas C, Jonas JJ. Dynamic transformation of deformed austenite at temperatures above the $\mathrm{Ae}_{3}$. Progress in Materials Science. 2016;82:15I-233.

Received: I Nov. 2019

Accepted: 14 Nov. 2019 